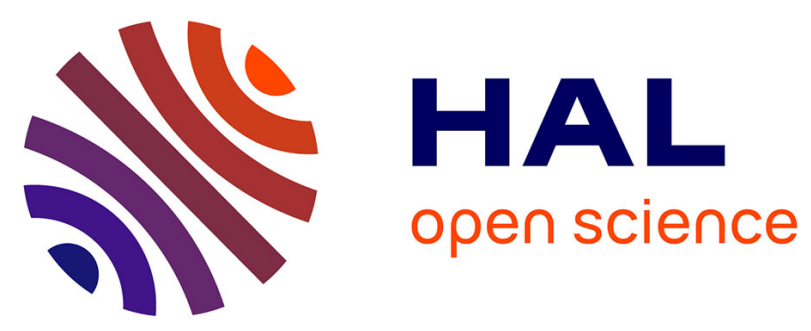

\title{
Experiments and 3D simulations of flow structures in junctions and their influence on location of flowmeters
}

Emmanuel Mignot, H. Bonakdari, P. Knothe, G. Lipeme Kouyi, Anne Bessette, Nicolas Riviere, J.-L. Bertrand-Krajewski

\section{- To cite this version:}

Emmanuel Mignot, H. Bonakdari, P. Knothe, G. Lipeme Kouyi, Anne Bessette, et al.. Experiments and 3D simulations of flow structures in junctions and their influence on location of flowmeters. Water Science and Technology, 2012, 66 (6), pp.1325-1332. 10.2166/wst.2012.319 . hal-00780133

\section{HAL Id: hal-00780133 \\ https://hal.science/hal-00780133}

Submitted on 22 Nov 2018

HAL is a multi-disciplinary open access archive for the deposit and dissemination of scientific research documents, whether they are published or not. The documents may come from teaching and research institutions in France or abroad, or from public or private research centers.
L'archive ouverte pluridisciplinaire $\mathbf{H A L}$, est destinée au dépôt et à la diffusion de documents scientifiques de niveau recherche, publiés ou non, émanant des établissements d'enseignement et de recherche français ou étrangers, des laboratoires publics ou privés. 


\title{
Experiments and 3D simulations of flow structures in junctions and of their influence on location of flowmeters
}

\author{
E. Mignot ${ }^{1}$, H. Bonakdari ${ }^{2}$, P. Knothe ${ }^{1}$, G. Lipeme Kouyi ${ }^{2}$, A. Bessette ${ }^{1}$, N. Rivière ${ }^{1}$, \\ J.-L. Bertrand-Krajewski ${ }^{2}$ \\ ${ }^{1}$ CNRS-Université de Lyon, INSA Lyon, LMFA, Bât. Joseph Jacquard, \\ 20 avenue A. Einstein, F-69621 Villeurbanne cedex, France \\ ${ }^{2}$ Université de Lyon, INSA Lyon, LGCIE (Laboratory of Civil \& Environmental Engineering) \\ F-69621 Villeurbanne cedex, France \\ *Corresponding author, e-mail: hossein.bonakdari@insa-lyon.fr
}

\begin{abstract}
Open-channel junctions are common occurrences in sewer networks and flow rate measurement often occurs near these singularities. Local flow structures are 3-dimensional, impact on the representativeness of the local flow measurements and thus lead to deviations in the flow rate estimation. The present study aims i) to measure and simulate the flow pattern in a junction flow, ii) to analyze the impact of the junction on the velocity distribution according to the distance from the junction and thus iii) to evaluate the typical error derived from the computation of the flow rate close to the junction.
\end{abstract}

\section{KEYWORDS}

Channel junction; flow pattern; flowmeters; laboratory experiments; CFD modeling

\section{INTRODUCTION}

Real time measurement of flow rates in sewers is a major task for sewer network practitioners. Typical sewer networks with dendritic structures include numerous junctions, defined as two (or more) upstream free-surface flows merging into one downstream flow. Flowmeters in sewers are often located in the vicinity of such junctions, either in the upstream or the downstream branches, for practical reasons, especially easy access from manholes.

The flow pattern in a free-surface- $90^{\circ}$-junction in subcritical regime has been described by authors such as Gurram et al. (1997) or Weber et al. (2001). The main flow structures highlighted by their results are: i) a recirculation region in the downstream branch where velocity magnitudes strongly decrease, ii) a contraction zone with a flow acceleration on the side of the recirculation region and iii) the presence of downstream secondary currents. Huang et al. (2002) and Shakibainia et al. (2010) used 3D models to compute flows in similar $90^{\circ}$ junction configurations and showed that most flow structures observed experimentally were accurately simulated. This is an important result as such junction structures often lead to systematic errors in estimation of flow rates when flowmeters are located in their vicinity. Indeed, processing of raw data and estimation of flow rate by flowmeters are based on hypotheses which are not verified near junctions: fully developed velocity profiles, axial symmetry in flow velocity profiles, etc.

The main objective of the present work is then to evaluate errors in flow rate measurements in the vicinity of sewer junctions. The applied approach consists to set up and validate a 3D 
numerical model to simulate accurately flow patterns through junctions and to use it in order to evaluate errors in flow rate measurements in various locations in both inlet and outlet branches when typical up-to-date commercial flowmeters are used.

\section{EXPERIMENTAL SET-UP}

Experiments are performed in the channel intersection facility at the Laboratoire de Mécanique des Fluides et d'Acoustique (LMFA) at the University of Lyon (France). The facility consists of three horizontal glass channels of $L=2 \mathrm{~m}$ length and $b=0.3 \mathrm{~m}$ width for each one. Channels intersect at $90^{\circ}$ with i) two inlet branches, labelled the "upstream branch" along the $x$ axis with flow rate $Q_{x i}$ and "lateral branch" along the $y$ axis with flow rate $Q_{y i}$ and ii) one outlet branch along the $x$ axis with flow rate $Q_{x o}=Q_{x i}+Q_{y i}$. Each inlet branch is connected to a large tank, from which water passes through a honeycomb structure to stabilize and straighten the inlet flows. The three parameters governing the flow configuration are the inlet flow rates $Q_{x i}$ and $Q_{y i}$ and the water depth $h_{d}$ at the extremity of the downstream branch which is controlled by a sharp crest weir. Due to negligible wall friction, the water depth is almost the same in all three branches; only a slight water depth increase appears in the inlet branches (maximum of $3 \%$ of $h_{d}$ ). A more detailed description of the experimental set-up is given in Rivière et al. (2006) or Mignot et al. (2008). The "reference configuration" corresponds to $Q_{x i}=Q_{y i}=2 \mathrm{~L} / \mathrm{s}$ and $h_{d}=0.12 \mathrm{~m}$. The assumed true values of flow rates in the facility are determined from calibrated pumps.

The velocity field is measured using a side-looking $16 \mathrm{MHz}$ SonTek® MicroADV (Acoustic Doppler Velocimeter). This device allows measuring the three velocity components $u, v$ and $w$ along the longitudinal $x$, cross $y$ and vertical $z$ directions respectively. Each measurement is recorded with a 120 second time step and a $50 \mathrm{~Hz}$ data acquisition frequency ensuring a stable time-averaged velocity. Thanks to the small size of the ADV probe, measurements can be performed as close as $1 \mathrm{~cm}$ from the free-surface and $2 \mathrm{~cm}$ from the channel walls. Measurements are performed at 11 wet cross-sections, with 42 measurement points across each wet cross-section ( 7 vertical lines $\times 6$ elevations).

\section{NUMERICAL METHODS}

The 3D numerical modelling is carried out by means of the commercial Ansys - CFX CFD software package, which solves the three-dimensional fundamental flow equations. As for most sewer flows, the experimental junction flow shows a high Reynolds flow number ( $R e \sim 15000-30000)$. An appropriate turbulence model is thus of great importance in order to obtain accurate numerical results. The key equations for fluid motion in the whole domain are: (1) the continuity equation for the incompressible fluid in Eulerian approach:

$\frac{\partial \overline{u_{i}}}{\partial x_{i}}=0$

and (2) the 3 Reynolds-Averaged Navier-Stokes (RANS) momentum equations for the incompressible turbulent fluid:

$$
\frac{\partial \overline{u_{i}}}{\partial t}+\overline{u_{j}} \frac{\partial \overline{u_{i}}}{\partial x_{j}}=-\frac{1}{g} \frac{\partial z}{\partial x_{i}}-\frac{1}{\rho} \frac{\partial P}{\partial x_{i}}+\frac{\partial}{\partial x_{j}}\left(v \frac{\partial \overline{u_{i}}}{\partial x_{j}}-\overline{u_{i}^{\prime} u^{\prime}{ }_{j}}\right)
$$

with $i$ and $j=1,2$ and 3, where $x_{i}$ represents the three coordinate axes, $\overline{\mathrm{u}_{\mathrm{i}}}$ the time-averaged velocity along axis $i, z$ the vertical free-surface elevation, $P$ the pressure, $\rho$ the fluid density 
and $\overline{\mathrm{u}_{\mathrm{i}} \mathrm{u}_{\mathrm{j}}{ }_{\mathrm{j}}}$ the Reynolds stresses with the "prime sign" referring to time fluctuations. Solving Eqs. 1 and 2 requires a turbulence model to set the Reynolds stresses. Among the proposed turbulence models, Bradbrook et al. (1998) and Shakibainia et al. (2010) have shown that the RNG (Re-Normalization Group) form of the $k-\varepsilon$ model (initially introduced by Yakhot et al., 1992) accurately computes the 3D behaviour of a junction flow. This turbulence model is then used for the present work.

Since Eq. 2 is elliptic, boundary conditions are required. Uniform velocity distributions are set at each inlet cross-section and outlet extremity water depth $h=h_{d}$ is specified. A sufficient length (10 meters) is provided upstream each inlet branch in order to obtain a fully developed turbulent velocity profile close to the junction. At the outlet, a hydrostatic pressure distribution is maintained across the entire cross-section. The rigid walls are considered smooth with no slip condition and the standard wall function method proposed by Launder and Spalding (1974) assuming a zero mean velocity at the walls is used. In order to keep the computational time compatible with systematic investigations and due to limited water depth variations observed in the experiments, the free surface is modelled as a rigid lid with freeslip conditions. This boundary condition ensures a zero shear stress at the free surface as observed in experiments. Lastly, the typical mesh size in the region of the junction is about $1 \mathrm{~mm}$. Having set the above key parameters (turbulence model, boundary conditions, appropriate computational meshes), no model calibration is needed.

\section{GENERAL FLOW PATTERN}

When two inflows meet at $90^{\circ}$ and merge, the flow in the downstream branch accelerates (see Fig. 1) as the downstream flow is the sum of both the upstream and the lateral inflows, while the water depth and thus the flow section remain constant. The lateral inflow (along the $y$ axis) being perpendicular to the main inflow (along the $x$ axis), a recirculation region extends in the outlet just downstream the lateral inflow. Velocities in this region are low and negative streamwise velocities are even observed near the side wall (see Fig. 1). The size (length and width) of this region is much larger at the free surface $(z \sim 0.12 \mathrm{~m})$ than in the near bed region $(z \sim 0.01 \mathrm{~m})$. Due to this change along the vertical axis, upward currents are present from the bed towards the free surface in the wake of the recirculation zone (see Fig. 2 at $x / b>3$ ) and coherent secondary currents are indeed observed in the experiments. On the side of the recirculation region, the flow accelerates in the contracted section (see Fig. 1 and Fig. 2 at $y / b \sim 0.83$ and $x / b \sim 2-4)$. Moreover, near the upstream corner of the junction $(x=y=0)$, a stagnation zone is observed (see Fig. 1), which strongly impacts the velocity distribution (magnitude and angle) along the lateral inlet $(y=0$ and $x / b=0-1)$.

When comparing measured and simulated velocity fields in Figs. 1 and 2, it appears that all flow structures described above and reported in the literature are accurately predicted by the numerical model in terms of magnitude, size and location. Moreover, similarities between measured and simulated velocities at the free surface confirm the validity of the rigid-lid boundary condition used for numerical simulations (see Fig. 1 at $z=0.11 \mathrm{~m}$ ). The main discrepancy between simulated and measured velocity fields concerns the vertical variation of the recirculation zone; indeed, while location and extension of the recirculation zone at the free surface are accurately predicted (see Fig. 1 at $z=0.11 \mathrm{~m}$ ), its extension in the near-bed region is overestimated by the numerical model (see Fig. 1 at $z=0.01 \mathrm{~m}$ ). 

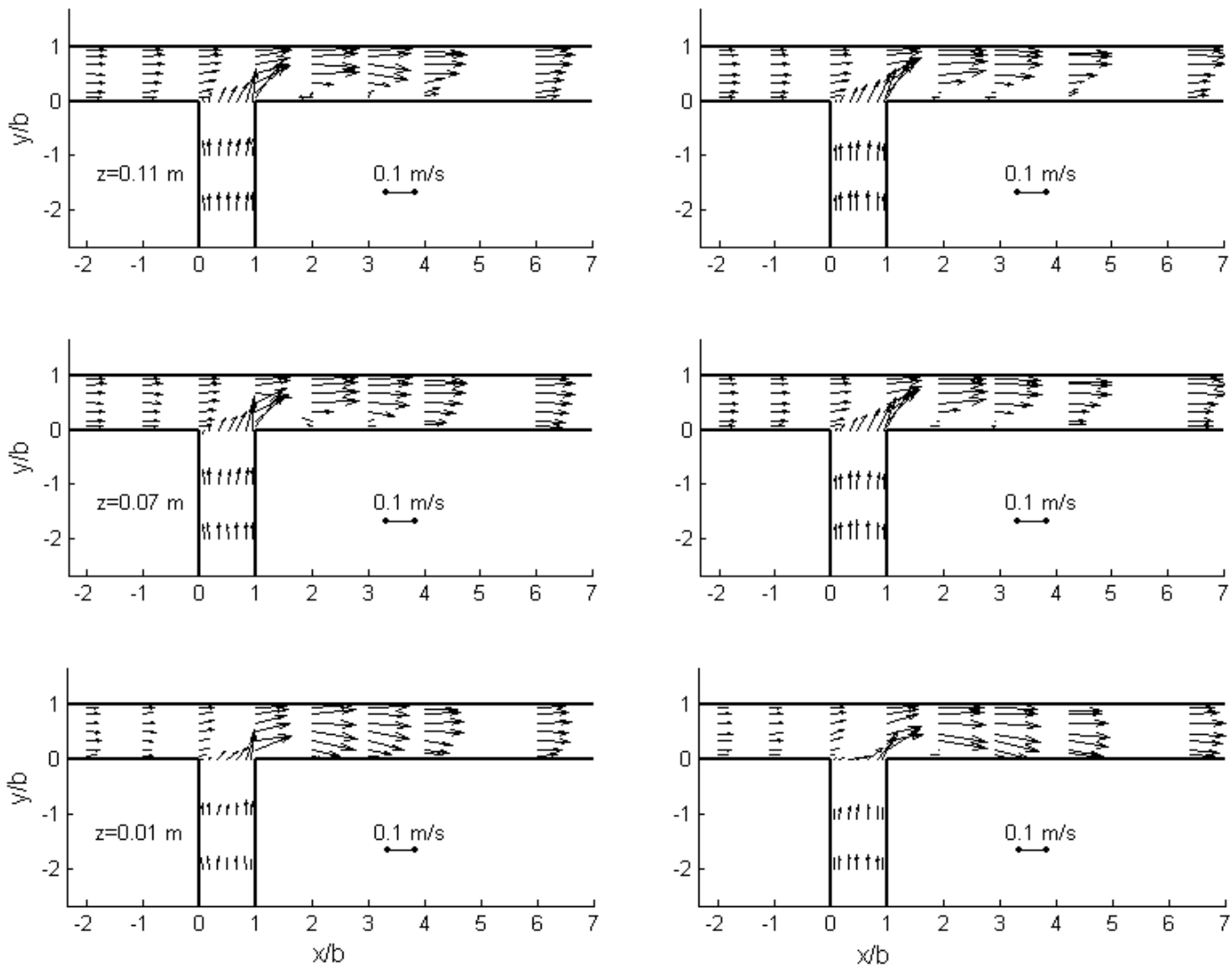

Figure 1. Horizontal velocity field $(u, v)$ at three elevations for the reference configuration: measured (left column) and simulated (right column).
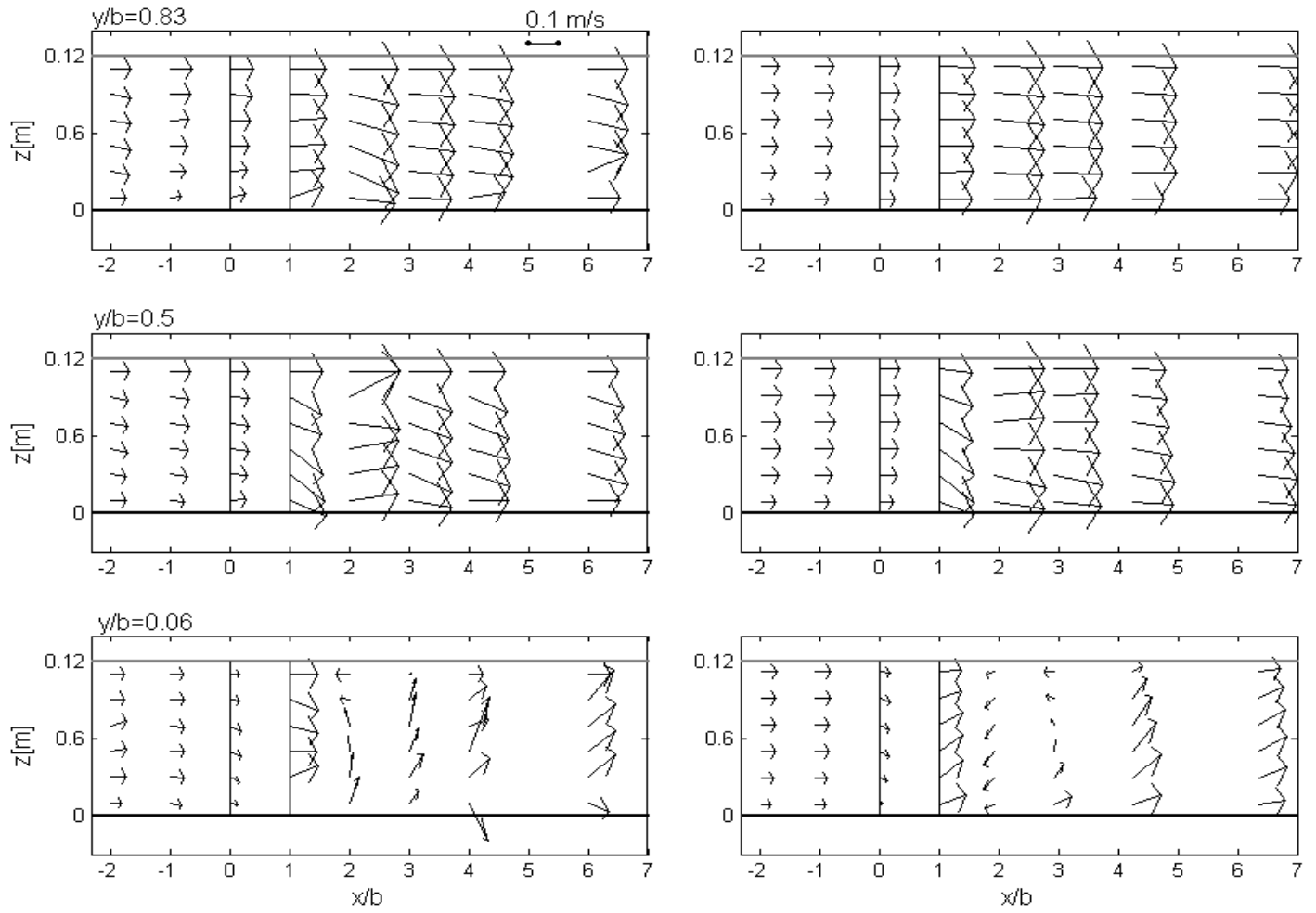

Figure 2. Velocity field $(u, w)$ in the main branch along three vertical lines (side views at constant $y$ values) for the reference configuration: measured (left column) and simulated (right column). 


\section{VELOCITY DISTRIBUTION IN MAIN CHANNEL SECTIONS}

Fig. 3 presents the streamwise velocity distribution at 3 sections in the inlet branch (Fig. 3a) and at 5 sections in the outlet branch along the $x$ axis (Fig. 3b). In the inlet, away from the junction, the streamwise velocity distribution is typical of a turbulent flow with streamwise velocities quite homogeneously distributed across the section, with strong decrease at the walls (see Fig. 3a for $x=-2 b$ ). When approaching the junction, this distribution is modified, the maximum streamwise velocity is moved towards the $y=b$ side wall while velocities decrease at the opposite side wall (see Fig. 3a for $x=0$ and Fig. 1 for all elevations).

In the outlet section (Fig. 3b for $x=b$ ), the distribution of streamwise velocities is surprisingly homogeneous, with streamwise velocities very close to the mean velocity $U_{M}$ in the whole section. When leaving the junction $(x \geq 2 b)$, the recirculation zone extends along the $y=0$ side wall. The distribution of streamwise velocities becomes very heterogeneous, with negative velocities in the recirculation zone and high positive velocities in the accelerated region along the opposite wall. Vertical and spanwise velocity gradients are then maximum in this section. Further downstream, the heterogeneity of velocity distribution decreases and the flow gradually returns to the typical open channel distribution observed in the upstream branch.

The quality of the experimental measurements can be verified by integrating the streamwise velocities across each section to determine the "measured flow rate" and by comparing it with the actual flow rate set by the calibrated pumps. We obtain a typical deviation of $1 \%$ in both the inlet $(x<0)$ and the outlet $(x>b)$ branches with a maximum deviation of $4.5 \%$ for $x=4 b$. Moreover, the right column of Fig. 3 confirms the agreement between the measured and simulated flow characteristics along the main channel. In the inlet branch, the maximum error in local streamwise velocity prediction equals $10 \%$, with magnitudes of velocity contours lower than those measured. In the outlet branch, the local error increases up to $50 \%$ in the recirculation zone. At $x=2 b$, negative velocity magnitudes are underestimated by the numerical model except in the near bed region (see $x / b=2-3, \mathrm{y}<b / 6$ and $z<50 \mathrm{~mm}$ ). Further downstream, the maximum error is located along the $y=0$ side wall, close to the bottom, but its magnitude rapidly decreases downstream.

\section{EFFECT OF FLOWMETER LOCATION}

The spatial heterogeneity of velocity distributions across sections near a junction has strong impacts on the flow rate determined by flowmeters. Indeed, commercial flowmeters in sewer networks (typically, but not exclusively, Doppler sensors) are usually located on the pipe invert at the centre of cross-sections (i.e. $y=b / 2$ and $z \sim 0$ ). They measure the vertical profile of streamwise velocities $u(z)$ by exploring the water column at a given angle from the central axis vertical line. Many sensors then average the vertical velocity profile to derive the depthaveraged streamwise velocity $V$ at $y=b / 2$ and multiply it by the cross-section area $S$ to compute the flow rate $Q$. Consequently, when the depth-averaged streamwise velocity at the centre of the channel $V$ departs from the mean cross-section velocity $U$, the error associated to the computed flow rate increases. To account for this effect, a correction factor $k$ may be introduced to estimate the mean cross-section velocity $U$ from the depth-averaged streamwise velocity $(U=k V)$. The correction factor, sometimes named calibration factor, is used to account for local geometry and roughness conditions. 

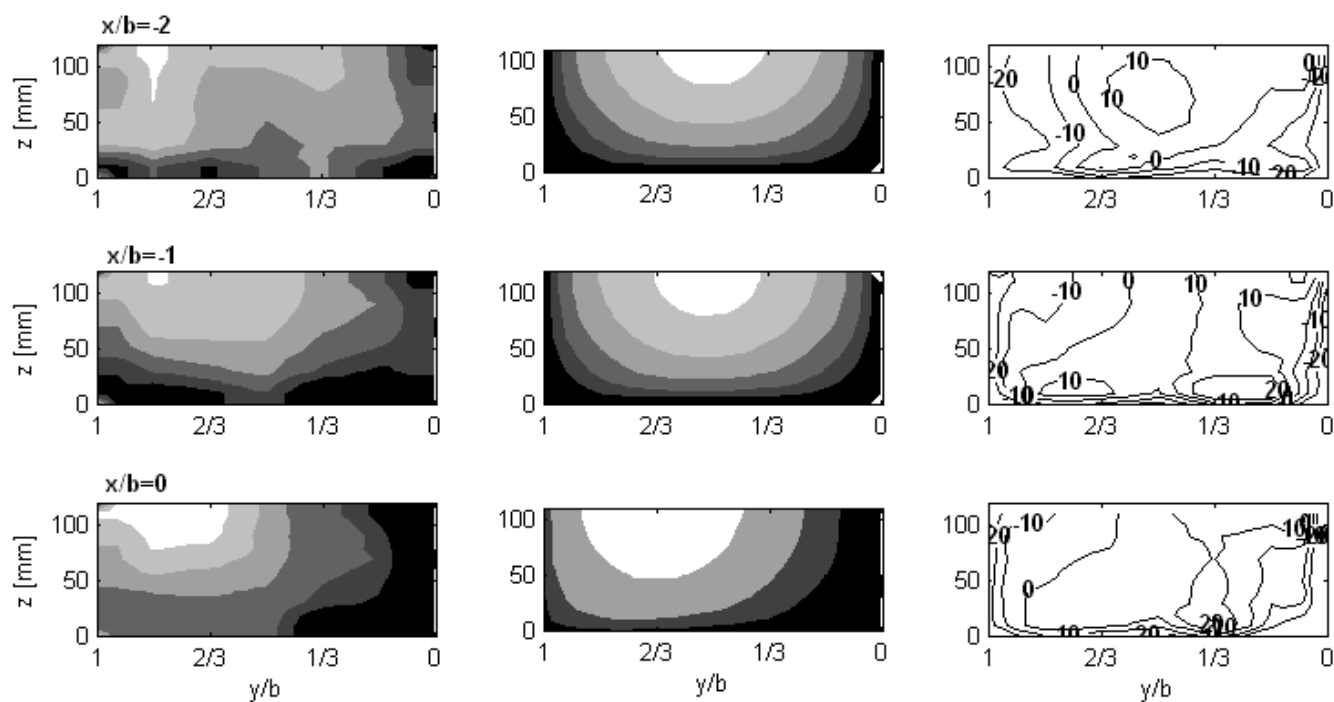

(a)
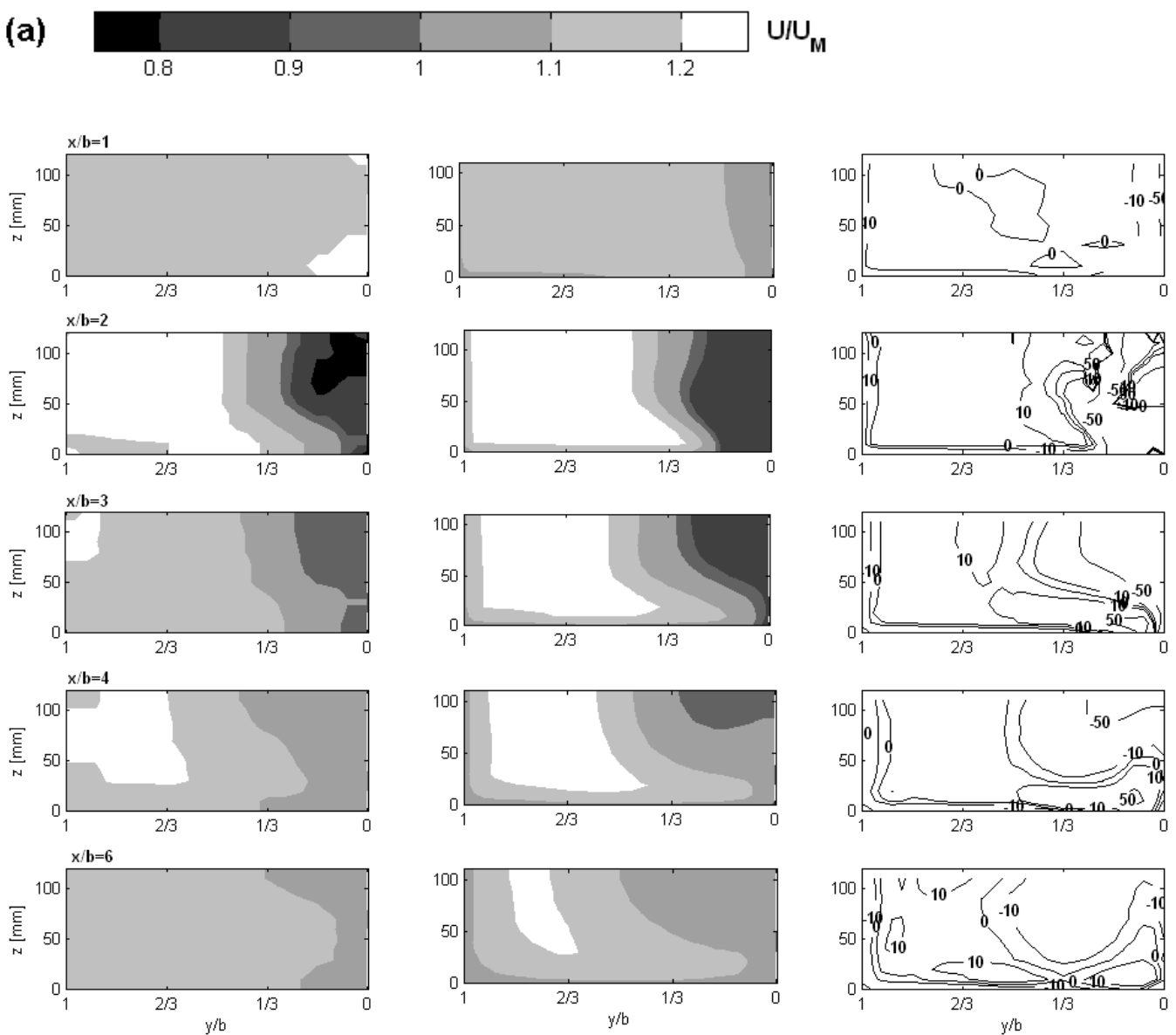

(b)

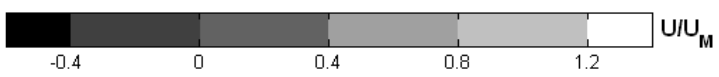

Figure 3. Streamwise velocity distribution across sections in the inlet (a) and outlet (b) branches of the main channel for the reference configuration. Measurements $\left(U_{E}\right.$ in the left column) and 3D simulations ( $U_{C}$ in the middle column) are expressed as $U / U_{M}$ with $U_{M}=Q / S$ the mean velocity, while deviations (in the right column) are given as $\left(U_{C^{-}} U_{E}\right) / U_{E}$ in $\%$.

In Fig. 4, measured and 3D simulated depth-averaged velocities $V$ at $y=b / 2$ have been multiplied by the wet cross-section $S(0.3 \mathrm{~m} \times 0.12 \mathrm{~m})$. In the inlet branch $(x<0)$, a maximum $14 \%$ overestimation of the flow rate is obtained if the measurement is performed at the entry 
section $(x=0)$. Indeed, Fig. 3 shows that, at $x=0$, velocity magnitudes along the central axis $(y=b / 2)$ are larger than those observed near the side wall $(y \sim 0)$. In the outlet branch $(x>b)$, a maximum $52 \%$ overestimation is obtained if the measurement is performed at $x / b \sim 1.8$. Such results are in agreement with those shown in Fig. 3 at $x / b=2$ where the velocity profile at the centre of the channel $(z=b / 2)$ is higher (white colour, that is larger than $0.12 \mathrm{~m} / \mathrm{s}$ ) than the measured mean cross-section velocity $U_{M}=0.11 \mathrm{~m} / \mathrm{s}$. Further downstream, as the flow distribution reaches the fully developed state, flow rate deviations rapidly decrease and become lower than $10 \%$ beyond $x / b=4.5$.

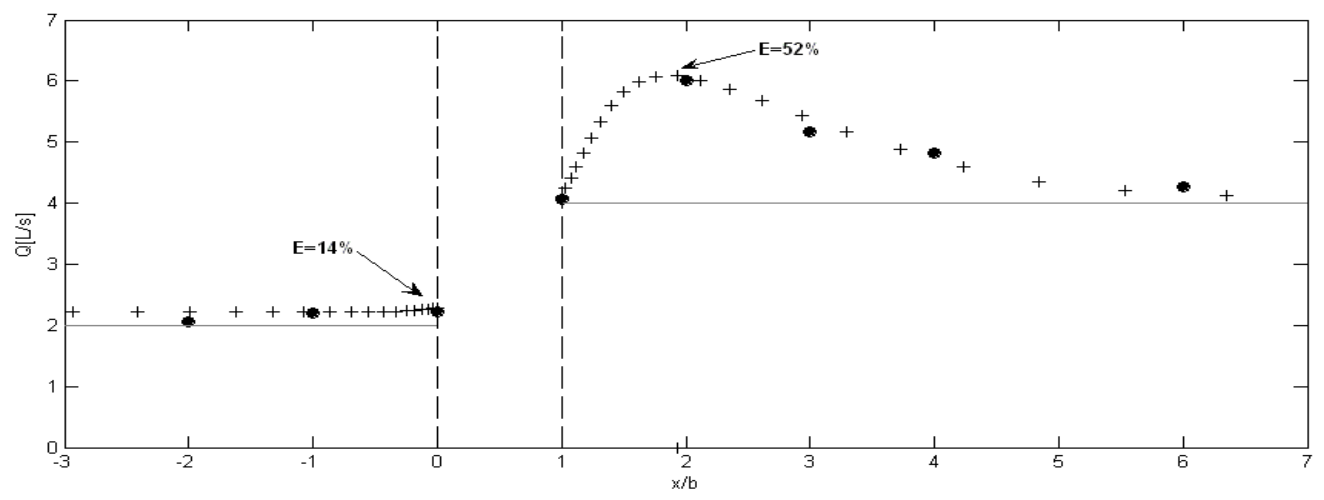

Figure 4. Assessment of errors $(\mathrm{E})$ and flow rates according to the location along the centre of the main channel: (straight line) $=$ experimentally set flow rate $Q,(+)=3 \mathrm{D}$ simulated flow rates and $(\bullet)=$ measured flow rates.

Moreover, Fig. 4 shows that experimental and 3D numerical results are very close each other. This gives confidence in the following extended analysis where only $3 \mathrm{D}$ numerical results are used for other flow configurations. The $3 \mathrm{D}$ numerical model is used to compute two additional flow configurations by keeping the same values $h_{d}=0.12 \mathrm{~m}$ and $Q_{x o}=4 \mathrm{~L} / \mathrm{s}$ and varying the upstream flow rates. For the $Q_{x i}=3 \mathrm{~L} / \mathrm{s}$ and $Q_{y i}=1 \mathrm{~L} / \mathrm{s}$ configuration, the accelerated flow region includes the plane at $y=b / 2$, as for the $Q_{x i}=Q_{y i}=2 \mathrm{~L} / \mathrm{s}$ reference configuration. Consequently, velocities at $y=b / 2$ remains larger than the mean cross-section velocity for all sections (see Fig. 5). This is also observed in Fig. 1 for all elevations.

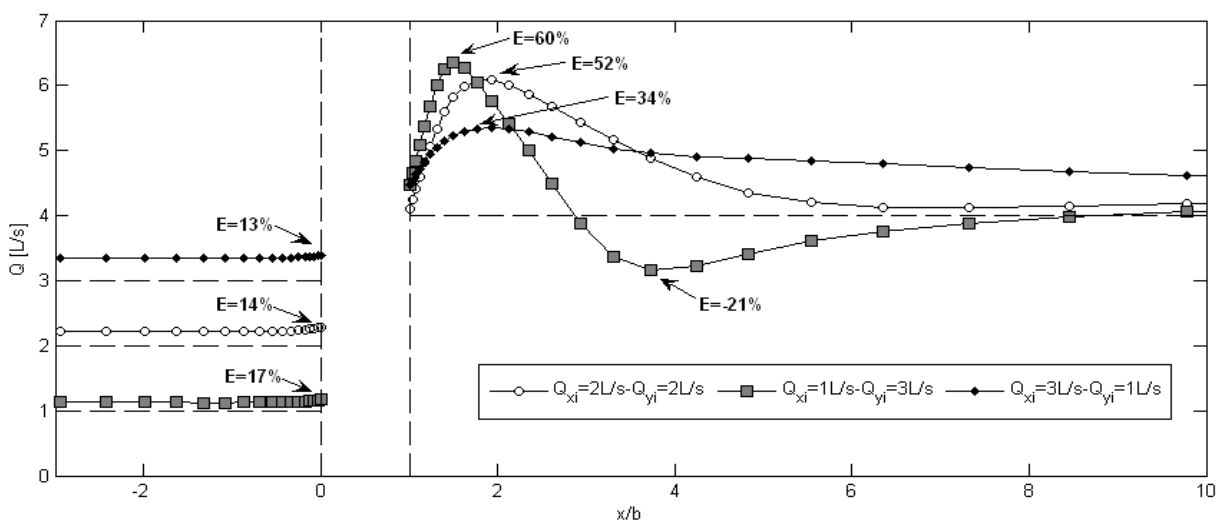

Figure 5. Assessment of flow rates errors (E) according to the location: (dashed line) = experimentally set flow rate $Q$ other symbols for $3 \mathrm{D}$ simulation results for three flow configurations (including the reference configuration).

For the $Q_{x i}=1 \mathrm{~L} / \mathrm{s}$ and $Q_{y i}=3 \mathrm{~L} / \mathrm{s}$ configuration, the width of the recirculation zone increases and almost reaches the value $y=b / 2$. Consequently, for $1<x / b<2.5$, the centre of the 
channel is within the accelerated zone and the mean depth-averaged velocity $V$ remains significantly larger than the mean cross-section velocity $U$ as for the two other configurations. However, for $3<x / b<9$, the $y=b / 2$ plane enters the wake of the recirculation zone and local velocities becomes lower than the mean cross-section velocity.

\section{CONCLUSION}

This study allows deriving the following main conclusions:

- A good agreement is obtained between experimental flow patterns and those described in the literature on flows in junctions.

- The 3D CFD modelling has been validated against experimental velocity data (profiles and contours of magnitude): it is an appropriate operational tool for flow calculation in complex and representative geometries.

- The evolution of streamwise velocity distributions along the main channel provides recommendations for flow meters location: they should be installed either in the upstream branch or in the downstream branch at a minimum distance $x / b=8$ from the junction for the tested configurations.

- Null error $(E=0)$ is observed at $x / b=1$ for the three computed configurations. If this is confirmed for other depths $h_{d}$ and downstream flow rates $Q_{x o}$, then it could be an appropriate location for measurements in real sewers. However, further simulations are required to confirm this preliminary conclusion.

- One main limit of the numerical approach arises from greater flow rates where free surface oscillations could require the use of the VOF (Volume Of Fluids) approach.

\section{ACKNOWLEDGMENTS}

The research was funded by the INSA Lyon BQR Program and the French INSU EC2COCytrix 2011 project No 231. Authors warmly thank C2D2 program carried out by DRI (French Minister of Environment) which bring funding for RGCU COACHS project.

\section{REFERENCES}

Bradbrook K.F., Biron P.M., Lane S.N., Richards K.S. and Roy A.G. (1998). Investigation of controls on secondary circulation in a simple confluence geometry using a three-dimensional numerical model. Hydr. Processes, 12(8), 1371-1396.

Gurram S.K., Karki K.S. and Hager W.H. (1997). Subcritical junction flow. J. Hydr. Engin., 123(5), 447-455.

Huang J.C., Weber L.J. and Lai Y.G. (2002). Three dimensional numerical study of flows in open channel junctions. J. Hydr. Engin., 128(3), 268-280.

Launder B.E. and Spalding D.B. (1974). The numerical computation of turbulent flows. Comp. Methods Appl. Mech. Eng., 3, 269-289.

Mignot E., Rivière N., Perkins R. and Paquier A. (2008). Flow patterns in a four branches junction with supercritical flow. J. Hydr. Engin., 134(6), 701-713.

Rivière N., Perkins R.J. Chocat B. and Lecus A. (2006). Flooding flows in city crossroads: 1D modelling and prediction. Wat. Sci. Tech., 54(6-7), 75-82.

Shakibainia A., Tabatabai M.R.M. and Zarrati A.R. (2010). Three dimensional numerical study of flow structure in channel confluences. Can. J. Civ. Eng., 37, 772-781.

Weber L., Schumate E. and Mawer N. (2001). Experiments on Flow at a $90^{\circ}$ Open-Channel Junction. J. Hydr. Engin., 127(5), 340-350.

Yakhot V., Orszag S.A., Thangam S., Gatski T.B. and Speziale C.G. (1992). Development of turbulence models for shear flows by a double expansion technique. Phys. Fluids, 4(7), 1510-1520. 